Portland State University

PDXScholar

\title{
A Comparison of Expressive Vocabulary Produced by Nonambulatory, Speaking Preschool Children and Ambulatory Speaking Preschool Children
}

Kim Denise Baker

Portland State University

Follow this and additional works at: https://pdxscholar.library.pdx.edu/open_access_etds

Part of the Speech Pathology and Audiology Commons

Let us know how access to this document benefits you.

\section{Recommended Citation}

Baker, Kim Denise, "A Comparison of Expressive Vocabulary Produced by Nonambulatory, Speaking Preschool Children and Ambulatory Speaking Preschool Children" (1992). Dissertations and Theses. Paper 4250.

https://doi.org/10.15760/etd.6134

This Thesis is brought to you for free and open access. It has been accepted for inclusion in Dissertations and Theses by an authorized administrator of PDXScholar. Please contact us if we can make this document more accessible: pdxscholar@pdx.edu. 
AN ABSTRACT OF THE THESIS OF Kim Denise Baker for the Master of

Science in Speech Communication with an emphasis in Speech-Language Pathology presented August 4, 1992.

Title: A Comparison of Expressive Vocabulary Produced by

Nonambulatory, Speaking Preschool Children and Ambulatory

Speaking Preschool Children

APPROVED BY THE MEMBERS OF THE THESIS COMMITTEE:

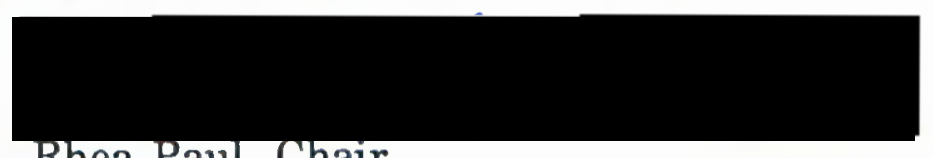

Rhea Paul, Chair

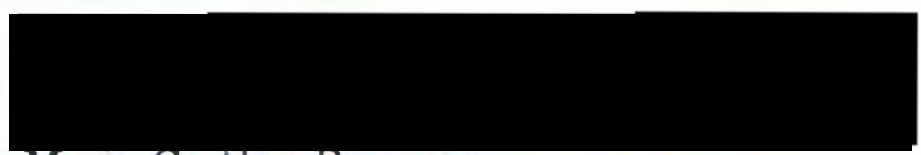

Mary Gordon-Brannan

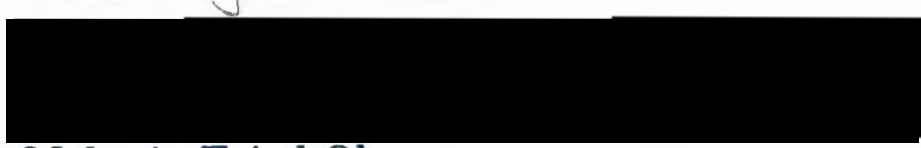

Melanie Fried-Oken

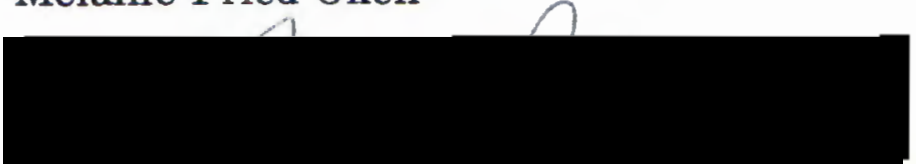

Ruth Falco

Children with severe physical disabilities often do not have the capabilities for oral communication. Professionals are frequently faced with selecting vocabulary for children who are unable to use vocal output because of severe motor impairments. A child who is nonambulatory may have additional reasons for communicating and sees the world from a different viewpoint than his ambulatory peers. Selecting appropriate words 
for an initial lexicon that are useful to nonspeaking disabled children that also meet normal language acquisition standards is a concern. This study specifically addresses this concern by looking at the vocabulary differences of ambulatory and nonambulatory preschool children. The purpose of this research project was to compare expressive vocabulary produced by nonambulatory, speaking children with the expressive vocabulary produced by ambulatory, speaking children. It is suggested that the vocabulary of nonambulatory, speaking children might be more appropriate for selecting a lexicon for AAC systems if indeed, they are different from words produced by ambulatory, speaking children.

Ten nonambulatory, speaking children between the ages of 3:0 and 7:0 years and 10 matched peers who were ambulatory served as subjects. The ambulatory children were normally developing in respect to receptive and expressive language, vision, and hearing, and sensory/motor skills. The children with mobility restrictions were unable to ambulate independently. A 1000-word language sample of each child was obtained during a play activity. The vocabulary was entered into a computer data base and compared for lexical agreement, lexical diversity, and commonality scores. The vocabulary items obtained were then compared to answer the following questions: 1) Are there differences between the percentages of lexical agreement of ambulatory and nonambulatory matched subject groups when individual language samples are compared to the top $15 \%$ of a composite vocabulary list? 2) Are there differences in the type-token ratios for ambulatory children and nonambulatory children? 
3) How many words are used in common to six or more subjects across the two subject groups? and 4) What words will be present in the lexicon of nonambulatory children and absent in the lexicon of their ambulatory peers?

Results indicate that no significant differences exist between ambulatory and nonambulatory children in the percentages of lexical agreement to a composite list of the top $15 \%$ of the most frequently occurring words. This suggests that the commonly occurring words come from the same vocabulary distribution, lending further support to the idea of a high frequency core vocabulary for all children. Low type-token ratios (TTRs) were obtained for all subjects and were not significantly different between the two groups. The TTRs are considered to be similar to those obtained in other studies. Ninety-six words were found to be common to six or more subjects in both subject groups and it was found that only 32 words were shared by all subjects. These results are interpreted to mean that nonambulatory children use words that are similar to their ambulatory peers and that the diversity of their vocabulary is not affected by their nonambulatory condition compared to ambulatory children of the same age. 
A COMPARISON OF EXPRESSIVE VOCABULARY PRODUCED BY

NONAMBULATORY, SPEAKING PRESCHOOL CHILDREN AND

AMBULATORY SPEAKING PRESCHOOL CHILDREN

by

KIM DENISE BAKER

A thesis submitted in partial fulfillment of the requirements for the degree of

MASTER OF SCIENCE

in

SPEECH COMMUNICATION:

with an emphasis in

SPEECH-LANGUAGE PATHOLOGY

Portland State University

1992 


\section{TO THE OFFICE OF GRADUATE STUDIES:}

The members of the Committee approve the thesis of Kim Denise Baker presented August 4, 1992.

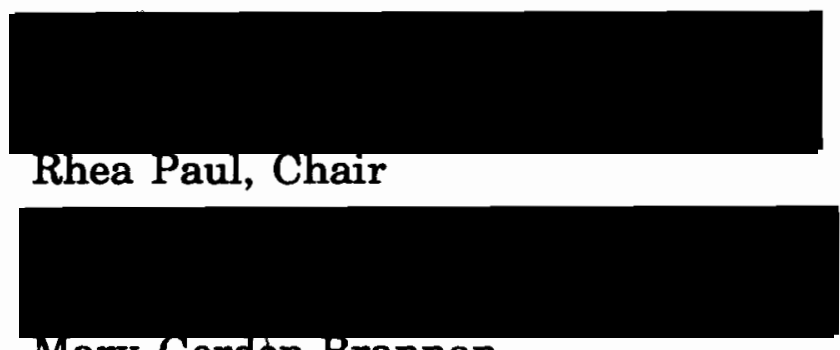

Mary Gordon-Brannan

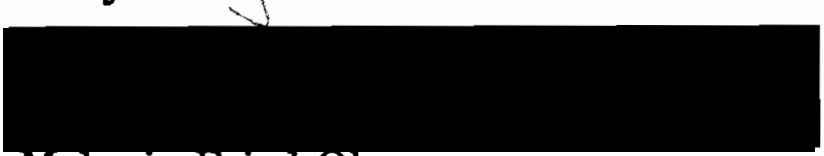

Melanie Fried-Oken

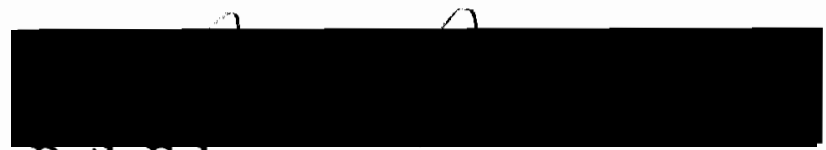

Ruth Falco

\section{APPROVED:}

Stepheh Kosokoff, Chair, Department of Speech Communication

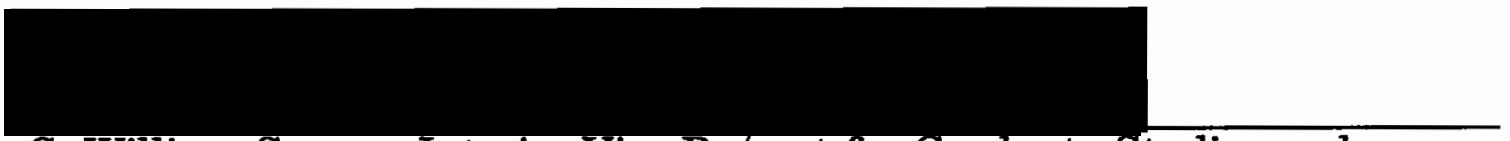

C. William Savery, Interim Vice Prøvost for Graduate Studies and Research 


\section{ACKNOWLEDGEMENTS}

Over the past two years I have had the support and encouragement of many people. I would like to thank Dr. Melanie Fried-Oken for allowing me to participate in her ongoing research in augmentative and alternative communication. I sincerely appreciate Melanie's constant support and encouragement. I would also like to thank my advisor, Dr. Rhea Paul, and the other members of my thesis committee, Mary Gordon-Brannan and Ruth Falco. The encouragement provided by Dr. Robert Casteel fostered growth in me as an individual and professional. In addition, I must thank my husband, Dr. Allen Baker, for his never ending support and sacrifice. 


\section{TABLE OF CONTENTS}

\section{PAGE}

ACKNOWLEDGEMENTS $\ldots \ldots \ldots \ldots \ldots \ldots \ldots \ldots \ldots$ iii

LIST OF TABLES $\ldots \ldots \ldots \ldots \ldots \ldots \ldots \ldots \ldots \ldots \ldots$, vi

LIST OF FIGURES $\ldots \ldots \ldots \ldots \ldots \ldots \ldots \ldots \ldots \ldots \ldots$ vii

CHAPTER

I INTRODUCTION AND STATEMENT OF PURPOSE .... 1

Introduction $\ldots \ldots \ldots \ldots \ldots \ldots \ldots \ldots, \quad 1$

Statement of Purpose ................ $\quad 2$

Definition of Terms ................ 3

I I REVIEW OF THE LITERATURE $\ldots \ldots \ldots \ldots \ldots \ldots \ldots$

Expressive Vocabulary Acquisition

of the Normally Developing Child .......... 6

Expressive Vocabulary Acquisition

for Children with Language Disorders ......

Expressive Vocabulary Acquisition of Children with Physical Disabilities from Spina Bifida Compounded by Hydrocephalus . .

Initial Lexicon Selection in Augmentative and Alternative Communication ...........

Summary $\ldots \ldots \ldots \ldots \ldots \ldots \ldots \ldots, \quad 21$

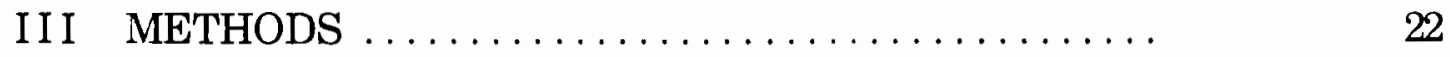

Subjects $\ldots \ldots \ldots \ldots \ldots \ldots \ldots \ldots \ldots \ldots \ldots \ldots, 22$ 


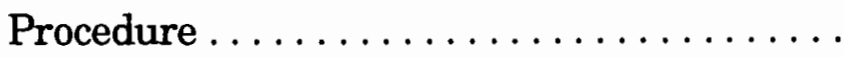

Data Collection

Data Transcription

Data Entry

Data Analysis . . . . . . . . . . . . . .

IV RESULTS AND DISCUSSION $\ldots \ldots \ldots \ldots \ldots \ldots \ldots$

Results $\ldots \ldots \ldots \ldots \ldots \ldots \ldots \ldots \ldots \ldots$

Discussion $\ldots \ldots \ldots \ldots \ldots \ldots \ldots \ldots \ldots \ldots$

V SUMMARY AND IMPLICATIONS . . . . . . . . . . 42

Summary .................... 42

Clinical Implications . . . . . . . . . . . 44

Research Implications . . . . . . . . . . . 46

REFERENCES $\ldots \ldots \ldots \ldots \ldots \ldots \ldots \ldots \ldots \ldots \ldots \ldots \ldots \ldots$

APPENDICES

A COVER LETTER AND INSTRUCTIONS TO PARENTS

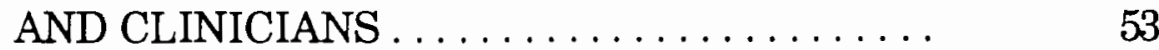

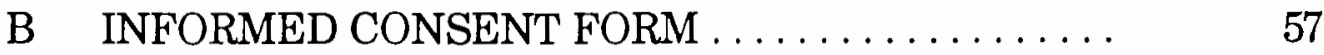

C GUIDELINES FOR COLLECTING LANGUAGE

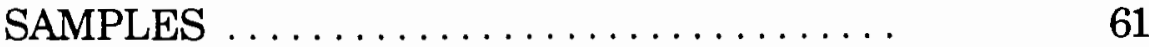

D STANDARDIZED TEST REPORTING FORM AND INSTRUCTIONS

E LIST OF WORDS UNIQUE TO NONAMBULATORY

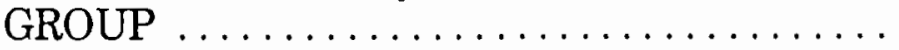




\section{LIST OF TABLES}

PAGE

TABLE

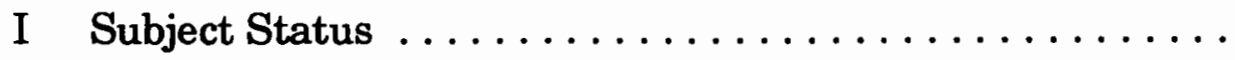

I I Percentage of Lexical Agreement Between Ambulatory and Nonambulatory Subjects and a Composite List of the 219 Most Frequently Occurring Words .......

III Summary of Lexical Agreement Percents for the Ambulatory and Nonambulatory Groups ........ 32

IV Type-Token Ratios $\ldots \ldots \ldots \ldots \ldots \ldots \ldots \ldots \ldots \ldots$

V Summary of Type-Token Ratios .............. 34

V I Types Common to Six or More Subjects ........... 35

VII Percentage of Words Common to Both Groups ........ 36 


\section{LIST OF FIGURES}

PAGE

FIGURE

I Percentage of Commonality for Nonambulatory and Ambulatory Group . . . . . . . . . . . . 


\section{CHAPTER I}

\section{INTRODUCTION AND STATEMENT OF PURPOSE}

\section{INTRODUCTION}

The development of augmentative and alternative communication systems for children requires one to look through the eyes of the learner. One must know what is important to the child to communicate about, what makes sense from his perspective of the world, the reasons for his communication attempts, and what words to start with to teach expressive communication. The process of selecting expressive vocabulary for the nonspeaking child essentially requires the professional to "put words in the nonspeaking child's mouth."

Professionals are frequently faced with selecting vocabulary for children who are unable to use vocal output because of severe oral motor impairments. Many of these children also present with mobility impairments which limit their ability to ambulate independently. However, there is a subgroup of youngsters who cannot speak but ambulate independently. A child who is nonambulatory may have some additional, unique reasons for communicating and may see the world from a different viewpoint than his ambulatory peers. When a child's ability to explore his environment and to interact with others is limited by his inability to ambulate independently, the development of communication skills can be 
expected to be impaired (Harris \& Vanderheiden, 1980). It is often necessary for professionals to select an appropriate initial lexicon for these nonspeaking, nonambulatory children.

Vocabulary for nonambulatory, nonspeaking children has been selected in a variety of ways but few empirically derived guidelines exist to assist the clinician in this important task. Frequently, vocabulary selection is based on vocabulary data from normally developing children. It is plausible that the expressive language acquired by children with mobility impairments and within normal expressive and receptive language skills could serve as a more appropriate model for choosing words for their peers with mobility impairments and severe expressive communication disorders.

\section{STATEMENT OF PURPOSE}

The purpose of this study is to compare expressive vocabulary produced by nonambulatory, speaking children with the expressive vocabulary produced by ambulatory, speaking children. It is suggested that the vocabulary of nonambulatory, speaking children would form a better database to select the vocabulary for nonambulatory, nonspeaking children. Results of this research will add to the database to be used for guidelines of initial core lexicon for the augmentative and alternative communication (AAC) systems of nonspeaking preschool children. To accomplish this goal, the following questions are posed: 
1. Are there differences between the percentages of lexical agreement for ambulatory and nonambulatory matched subject groups when individual language samples are compared to the top $15 \%$ of words in a composite list?

2. Are there differences in the range of type-token ratios for ambulatory children and nonambulatory children?

3. How many words are used in common words to six or more subjects across the two subject groups?

4. What words will be present in the lexicon of nonambulatory children and absent in the lexicon of their ambulatory peers?

\section{DEFINITION OF TERMS}

The following terms were used as operational definitions for this study:

1. Augmentative and Alternative Communication (AAC). Refers to any strategy, technique, or device designed to enhance verbal speech and to be used when verbal speech is not used (Baumgart, Johnson, \& Helmstetter, 1990).

2. Cerebral Palsy. A neurological condition caused by injury to the brain, primarily at the motor control center. Characteristics may include too little muscle tone, abnormal positioning, and general lack of coordination. Associated problems include: mental retardation, hearing, speech, vision, as well as problems of perception (Love \& Webb, 1986).

3. Commonality Score. A number that represents the number of subjects using a particular word (i.e. a score of 10 indicates that all ten subjects in one group produced the word, and a score of one would indicate that only one subject used the word).

4. Core Yocabulary. A set of words which, because of frequency of use or utility to the user, appears on most communication devices (Yorkston, Dowden, Honsinger, Marriner, \& Smith, 1988). 
5. Hydrocephalus. "Excessive accumulation of cerebrospinal fluid in the ventricles of the brain due to blocked fluid circulation, resulting in compression of the brain and eventually enlargement of the head" (Williamson, 1987, p. 211).

6. Nonambulatory. A condition where the individual is unable to use independent, unassisted ambulation as the primary mode of mobility.

7. Lexical Agreement. A measurement of the common words in each individual language sample and the entire vocabulary pool (Beukelman, Yorkston, Poblete, \& Naranjo, 1984).

8. Nonspeaking. A condition where the individual is unable to use oral speech as the primary mode of communication.

9. Spina bifida. A congenital malformation of the spine due to the vertebrae failing to fuse or close (Williamson, 1987, p.1).

10. Type. Unique or different words included in a language sample.

11. Token. The total number of words included in a language sample. 


\section{CHAPTER II}

\section{REVIEW OF THE LITERATURE}

Where does one begin to find words for the augmentative and alternative communication of young nonambulatory, nonspeaking children? The children are too young to choose words themselves and few guidelines have been set. One vocabulary source would be vocabulary of speaking, nonambulatory children. Research on expressive vocabulary acquisition by speaking, nonambulatory children has been conducted for children with spina bifida and hydrocephalus (Horn, Lorch, Lorch, \& Culatta, 1985; Swisher \& Pinsker, 1971; Tew, 1979). Unfortunately there are no studies published on vocabulary acquisition for speaking children with cerebral palsy and nonambulatory conditions. Research on vocabulary development for nonambulatory children has direct implications for nonambulatory children who cannot speak and must rely on augmentative and alternative (AAC) devices. The words acquired by nonambulatory speaking children might be good models for the vocabulary selection process in AAC. Another source might be the vocabulary of normally developing children or vocabulary development of children with language disorders. All of these children, however, bring different skills and needs to the process of language learning. This chapter will review research on expressive vocabulary development of the normally developing child, initial 
lexicon selection for children with early expressive language disorders, expressive vocabulary development in children with spina bifida compounded by hydrocephalus, and vocabulary selection for the augmentative and alternative communication devices of nonambulatory nonspeaking children.

\section{EXPRESSIVE VOCABULARY ACQUISITION OF THE NORMALLY DEVELOPING CHILD}

As children grow, their development proceeds predictably, although individual differences exist, and they reach developmental milestones at approximately the same age and go through similar developmental phases or periods (Owens, 1988). Many psycholinguists (Nelson, 1973; Clark, 1973; Benedict, 1977) have studied early expressive vocabulary development of able-bodied children, examining the meanings of the words spoken as well as the functions of the words in an effort to identify developmental milestones or language universals.

During the experimental semantic revolution of the 1970's, researchers began studying the meaning behind children's words, not only the grammar of the language. Nelson (1973) generated a list of the first 50 words produced by normally developing speaking children. The list was divided into six categories. Nelson found that two distinctly different groups could be formed when analyzing the data of children's first 50 words produced. Some children express many more nominals in their first 50 words while other children express many more social- 
personal words. Nelson classified these two distinct groups as referential and expressive language learners, respectively, noting that the function of the language seems to influence its content.

Some have theorized that vocabulary development can be divided into two parts: comprehension and production. Goldin-Meadow, Seligman, and Gelman (1976) examined the two-year-old's comprehension and production of nouns and verbs. They found a Receptive group and a Productive group of language learners. The Receptive group were the children who understood almost three or more times as many nouns as they said and produced no verbs at all although they understood many. The Productive group contained subjects who said almost every noun they understood and produced verbs though not as many as they understood. A longitudinal study was conducted to show that these two groups compose two successive stages rather than two different types of language learners. All subjects in the Receptive group showed a change in their skills similar to the Productive group. Additionally, results indicated that 2-year-olds do not begin to produce verbs until sometime after they have begun producing several nouns. Their data suggest that one cannot make judgements on a child's comprehension of vocabulary based only on production data, nor can one make judgements on a child's production of vocabulary based solely on comprehension data.

Benedict (1977) found a distinction in early lexical production and comprehension development in her study, as well. The study was conducted in two phases beginning when the subjects were between nine 
and ten months of age and ending when the child's mean length of utterance exceeded 1.10 or the child reached the age of $2: 0$, whichever came first. During the first phase of the study, parents maintained an ongoing diary record of their child's receptive and productive language. When the children reached approximately 1:0 year old, mothers were asked to fill out word checklists for the words understood by their child and the comprehension diary was terminated. The production diary continued until the list of the child's first 50 words produced was completed. Additionally, the experimenter visited the family in their home and recorded observations of the child's receptive and productive use of language. All information was then compiled into one diary where all demonstrations of the child's comprehension and production of a particular word were recorded. Analysis of all data showed that comprehension developed much more rapidly than production. On the average, children understood 50 words before they were able to produce 10 words and that comprehension of 50 words sequentially was ahead of production of 50 words by approximately 5 months. Additionally all major word classes were represented in the first 50-word vocabularies. In 1989, Beukelman, Jones, and Rowan studied the expressive vocabulary of preschoolers. Three-thousand-word language samples were obtained from six preschool children during classroom activities. A list of the 250 most frequently occurring words was developed from these samples and a commonality score was calculated for each. Each subject used all of the first 25 words of the list at least once in his or her language sample. These 
words represented nearly half $(45.1 \%)$ of each language sample. Eighty-five percent of the total sample was expressed by the 250 most frequently occurring words. These results indicate that vocabulary usage is commonly shared among preschool children.

Since normally developing children acquire language in a predictable manner, one might consider choosing expressive lexical items that appear frequently in lists of children's first words when selecting vocabulary for the nonspeaking, nonambulatory child. As Nelson (1973) points out, though, the function of the language seems to influence its content. It is probable that the nonspeaking, nonambulatory child has additional reasons for using language compared to the ambulatory child, therefore the content of his speech may well be different from that of the normally developing child.

\section{EXPRESSIVE VOCABULARY ACQUISITION FOR CHILDREN WITH LANGUAGE DISORDERS}

Clinicians are faced with quite a challenge when deciding what words to include in teaching an initial lexicon to children with a language disorder. Researchers such as Holland (1975) believe that the predictable patterns of language development in normally developing children can be applied to the diagnosis and intervention with children who have a language disorder. Holland (1975) stated that intervention with language-disordered children should parallel normal language acquisition. She listed several considerations in choosing an initial lexicon 
for children who have a language disorder: 1) use normal language development patterns as a model; 2) emphasize what is important to the child; 3) realize the importance of communication rather than merely language skills; and 4) focus on objects and events that are in the "here and now." Based on these points of consideration, Holland presented an initial core lexicon of 35 items, including general vocabulary as well as specific words for individual use.

Lahey and Bloom (1977) also described several criteria for choosing a first lexicon for intervention with children who have a language disorder. Besides the considerations suggested by Holland (1975), Lahey and Bloom recommended three additional criteria. They felt that the content, form, and use of the vocabulary were each important factors in selecting appropriate first words. The first lexicon should contain words that could be demonstrated nonlinguistically. Particular words need to be useful and functional for the child. Finally, they recommended that the lexical items be organized according to the ideas they encode or content categories. These categories are action, entity, attribute, possession, agent, locative, recurrence, object, negation, and demonstrative.

For persons with a severe communication impairment, sign language may be used as an expressive mode of communication in addition to or in conjunction with speech (Reichle, Williams, and Ryan, 1981). Once again, though, the clinician is faced with the colossal task of planning an initial expressive lexicon. Fristoe and Lloyd (1980) proposed a 50-item list of signs to be considered in developing an initial sign lexicon for persons who 
have normal hearing but who have not been able to learn spoken communication. They used normal language development as a model for development of the initial expressive sign lexicon for mentally retarded and autistic individuals with expressive impairments. They used a variety of sign manuals designed for use with severely handicapped individuals to develop a database of many frequently appearing signs. Each sign was then scrutinized using the developmental criteria set forth by Holland (1975) and Lahey and Bloom (1977) and signs were added and deleted to attain the proposed initial sign lexicon. Fristoe and Lloyd based the size of their initial lexicon on the single-word stage because speaking children usually have an expressive vocabulary of approximately this size when they begin to use two-word phrases (Nelson, 1973). Additionally, they suggested that relational words that are less specific have the greatest potential for communication in a variety of situations. Substantives, words used to refer to particular objects or categories, should be chosen based on those objects or categories most frequently encountered by the child.

In 1983, Karlan and Lloyd tested the social validity of the initial sign lexicon proposed by Fristoe and Lloyd (1980). Judges were asked to rate the vocabulary items as either: a) essential to; b) useful in; c) could be useful in; or d) of no value when designing an initial expressive vocabulary. Results showed that none of the 84 items were rated as "of no value". Social validation of word lists may help to determine the appropriateness of vocabulary for nonspeaking children in their various environments. Another potentially helpful guideline in selecting first words for 
nonspeaking children may be developmental language inventories such as those presented by Rescorla (1989) and Reznick and Goldsmith (1989). These early word checklists were intended to be helpful in documenting language delay in toddlers. These checklists include words that are found to be within the average two year old's expressive vocabulary. In The Language Development Survey (Rescorla, 1989), parents in a pediatrician's office were asked to check off words from a 300 word list that their child used spontaneously and to write down three of the child's sentences if the child was able to combine words. Results indicated that parent report on this checklist was highly correlated with the child's performance as measured by standard expressive language tests. In an attempt to provide a less cumbersome checklist, Reznick and Goldsmith (1989) developed five non-overlapping sublists from the Communicative Development Inventory (CDI) WORDS (Bates, Bretherton, \& Snyder, 1988) checklist that included 123 words each. Parents of 25 infants were asked to check the words that they had heard their child use. Analysis of the data showed that the five lists were comparable and reflected the normal course of language development, providing an acceptable option for the CDI WORDS checklist. If the words are found to be within the language of toddlers, then they should be considered as candidates for initial lexicon selection for 3-6 year old nonspeaking children.

Dale, Bates, Reznick, and Morisset (1989) reported data collected from three research projects that dealt with the usefulness of parent report as a measure of children's expressive language. Three samples representing a 
diverse sample including fullterm infants, high risk infants, and preterm infants were analyzed. The results showed that parent report of children's expressive language is a useful tool at 20 months regardless of the social economic status of the family and the literacy skills of the parent making the report.

In summary, several researchers have suggested that intervention with children who have a language disorder should parallel normal language acquisition. A few word checklists and core lexicons have been proposed as guidelines for children who have language disorders based on the developmental patterns of the normally developing child. It is not evident that any of the research, thus far, includes children who are nonambulatory. It is questionable then whether these guidelines should be generalized to that population. If studies have not been conducted to gain information regarding the normal development of nonambulatory children, how can one be certain that their language develops in the same predictable manner as the ambulatory child? If the developmental pattern of the nonambulatory child differs significantly from the patterns of the normally developing child, it is questionable whether the interventions used with ambulatory language disordered children should be applied to nonambulatory, nonspeaking children.

EXPRESSIVE VOCABULARY ACQUISITION OF CHILDREN WITH PHYSICAL DISABILITIES FROM SPINA BIFIDA COMPOUNDED BY HYDROCEPHALUS

Children with spina bifida compounded by hydrocephalus often 
present with nonambulatory conditions and preserved oral speech. Children who have spina bifida and hydrocephalus are the only nonambulatory population whose expressive language has been studied. Spina bifida is a neurological dysfunction caused by failure of the bones in the spinal column to enclose the spinal cord during the first trimester of pregnancy. The physical abilities of children with spina bifida vary significantly but generally their range of motion in joints is limited, muscle tone is abnormal presenting either hypotonia or hypertonia throughout the body, muscle strength may be limited, sensations such as pain, temperature, and touch may be impaired, movement skills are severely impaired, and postural control is unstable (Williamson, 1987). Children with spina bifida are frequently nonambulatory. In the majority of children with spina bifida, hydrocephalus is present, also (Williamson, 1987). Hydrocephalus is a condition where excessive cerebrospinal fluid is accumulated in the brain due to the blocked fluid circulation. This causes compression of the brain and eventually enlargement of the head.

The characteristics of speech and language development in children with spina bifida and hydrocephalus, a nonambulatory, speaking population, are somewhat peculiar (Schwartz, 1974). Language development skills apparently follow the normal pattern of development for these children but they frequently display a unique type of language production known as "The Cocktail Party Syndrome" (Fleming, 1968). They are excessively verbal and their language production consists of statements that are out of context, automatic phrases, and cliches (Schwartz, 1974). In 
1974, Schwartz noted that cocktail party speech seemed to be less prevalent and fewer occurrences were being documented than in years past. She suggested that occurrences of cocktail party speech may not be decreasing, rather that it is better controlled by the treatment provided for these children and the environments they are able to experience. She theorized that the smaller number of occurrences was possibly due to the "earlier age at which the children are standing, walking, and gaining greater independence" as well as other factors. She also made note of the fact that children become more mobile earlier with the improved treatment they receive. Earlier mobility allows children the opportunity to encounter more "world-experiences," thereby reducing bizarre speech episodes.

In 1979, Tew studied the language of 49 children with spina bifida cystica to determine if children with cocktail party syndrome are distinguishable from other cases of hydrocephalus and spina bifida. The subjects formed two groups. The first group, the Cocktail Party Syndrome (CP) group, consisted of children who were judged to show the syndrome if they displayed at least four of five specific criteria. The second group, the Spina Bifida (SB) group, did not display characteristics of cocktail party speech. All subjects were matched with control subjects for sex, place in family, social class and their area of residence. It was discovered that $85 \%$ of the CP cases were assessed as having a severe physical disability while only $48 \%$ of the SB group were considered to have a severe physical disability. Administration of the Revnell Developmental Language Scales (Reynell, 1969) showed a significant difference in scores between the two 
groups. Expressive and receptive language scores for the CP group were approximately two and a half years below their chronological age while the SB group exhibited an approximate delay of only six months. Using the Vineland Social Maturity Scale (Dahl, 1965), statistically significant differences were observed between the two study groups. The CP group showed evidence of significantly poorer social maturity. Tew suggested that the poor social maturity may be due in part to the severe physical handicap.

In 1971, Swisher and Pinsker studied children with spina bifida cystica and a history of hydrocephalus to answer three questions: a) Can the verbal output considered by clinicians to be hyperverbal be measured objectively in an informal conversational situation? b) What is the quality of the output of these children? and c) Is superficiality of their output reflected on the Illinois Test of Psycholinguistic Abilities (ITPA) (McCarthy \& Kirk, 1961). Eleven subjects between the ages of 3 years, 2 months and 7 years, 10 months were included in the study. They were all considered to be hyperverbal by their clinicians, had sustained a shunting procedure for hydrocephalus, and were Caucasian. Control subjects were born with one or more extremities missing and were matched to the subjects based on age, history of a congenital physical handicap, and history of exposure to hospitalizations and clinical appointments. The interviewer engaged each child in a 5-10 minute conversation directly followed by administration of the ITPA. Results indicated that the hydrocephalic group used significantly more words and vocal response units and initiated more 
speeches than the control group during conversation. An analysis of the quality of the verbal output by the hydrocephalic group showed that these children used significantly more inappropriate and bizarre language than their controls during the informal conversation with the interviewer. Results of the formalized testing showed that the average standard scores of the hydrocephalic group were below those of the control group on all subtests which reflected the superficiality of their output. Although these children seem to produce more speech, it is characteristically more bizarre and inappropriate. Because these children have the ability to produce automatic language, they seem to use their ability to excess, creating language production that is used on a superficial but social level.

It is apparent from Schwartz's 1974 study and Tew's 1979 study that earlier mobility and increased independence influences these children's expressive language. Although these results are striking, one cannot generalize them to all nonambulatory populations. The present study seeks to discover information regarding nonambulatory children's expressive language who do not have spina bifida and hydrocephalus.

\section{INITIAL LEXICON SELECTION IN AUGMENTATIVE AND} ALTERNATIVE COMMUNICATION

Much of the literature on vocabulary selection in AAC is clinically oriented rather than supported by actual research documentation (Beukelman, McGinnis, \& Morrow, 1991). There is no standard method for selecting vocabulary. Several authors have suggested a formal approach to 
vocabulary selection (Blau, 1983; Carlson, 1981; Meyers, Anderson, \&Liddicoat, 1984; Morrow, Beukelman, \& Mirenda, 1989; Porter, 1987). The use of environmental inventories, core vocabularies created for different populations of persons with language disabilities, and fixed vocabularies of communication aids dominate the literature.

Carlson (1981) suggested an environmental approach to vocabulary selection. An environmental inventory is simply a written record of daily events that the nonspeaking person experiences and observes. Parents, teachers, and significant others make an undiluted list of vocabulary words that could promote communication interaction for the various environments. From this pool of vocabulary words, "words which [are] within the child's developmental experience and interest level [are] selected for symbolization" (Carlson, 1981, p. 243). The remaining words are set aside until the child is ready for a larger or more varied lexicon. Carlson claimed that this process is open ended and sensitive to developmental and environmental changes.

Porter (1987) and Meyers, et al. (1984) suggested that observation and interview should play a major role in the vocabulary selection process. Children should be observed in a variety of communication environments and while interacting with their primary caregivers. Meyers et al. (1984) noted the importance of interviewing parents, teachers, therapists, and friends of nonspeaking children to provide significant information regarding children's specific communication needs. She grouped communication needs into four areas: school, recreation, basic physical 
needs, and feelings from which caregivers are instructed to select words from each area.

Morrow, et al. (1989) compared three methods of vocabulary selection with the help of parents, speech-language pathologists, and teachers of six nonspeaking children. A vocabulary checklist was presented to each of the informants and they were asked to check off the words they felt were essential or useful to the children. Subjects then completed a categorical interview. Basic categories were listed and the informants were asked to fill in desired vocabulary under each category. For example, they listed words in categories such as people, activities, actions, and feelings. In the third approach, informants were provided with a blank sheet of paper and asked to simply list their own choices for vocabulary items. Analysis of the three methods revealed that while the checklist yielded the most words, the blank page yielded the most unique words. The informants rated the checklist as the most satisfactory, fastest, and easiest to complete of the three processes. Morrow et al. theorized that a core vocabulary checklist that supplied most of the words could be utilized since only 25 percent of the words selected for each subject were actually unique. They also suggested that interviews with parents, siblings, teachers, and peers could be used to choose words that were unique to the individual child.

The development of a core vocabulary for AAC users is supported by many clinicians (Blau, 1983; Meyers et al.; Wilson, 1980, 1984). In an attempt to develop a core lexicon for persons using AAC, Wilson (1980) believed that one must consider the individual, his environment, the 
characteristics of the specific system, and normal language acquisition. Specific research on the development of a core vocabulary has been conducted with adolescent and adult nonspeaking populations. Yorkston, Smith, and Beukelman (1990) compared the advantages of custom-made word lists and standard vocabulary lists from communication devices and other sources. They found that standard lists contained many words that were rarely or never used by a particular individual while the custom-made word lists were used extensively. Their data suggest that standard word lists can serve as a resource of potential words to be included in an AAC device, but must be individualized.

More (1990) compared the words selected by the caregivers of nonspeaking preschool children to the words available on different communication aids. She found that the word lists on communication aids differ in both size and content. Some were more appropriate for preschoolers than others based on her preschool composite list and some were far too long to make efficient use of time. Through collection of data from thirty 100-word lists generated by parents and clinicians, a 293-word respondent composite list was developed, representing common words to 10 percent of the respondent lists. She proposed this list for selecting vocabulary words for an initial expressive vocabulary. It was developed specifically for preschool children, represents a high degree of their vocabulary needs, and contains words that are developmentally appropriate and appear on a number of communication aids.

Several approaches have been used in selecting vocabulary for AAC 
users including: environmental inventories, observation and interview, vocabulary checklists, categorical interviews, core vocabularies, and standard word lists. All of these methods seem viable but one must question their appropriateness for a nonambulatory, nonspeaking child.

\section{SUMMARY}

A review of the literature shows that few guidelines are available for selecting expressive vocabulary for nonspeaking, nonambulatory preschool children. These available guidelines are based on words spoken by children who ambulate independently. If, indeed, independent ambulation affects early vocabulary growth, these sources may not be appropriate for nonambulatory, nonspeaking children. A vocabulary source for the nonambulatory, nonspeaking children is needed that is based on words spoken by nonambulatory children. This study will investigate the differences in vocabulary production between ambulatory and nonambulatory preliterate children. It will investigate whether the vocabulary spoken by ambulatory children is similar to that of nonambulatory children and how much variety each group uses. If differences are found between the two groups, then recommendations for establishing a core vocabulary for AAC systems based on words spoken by the nonambulatory youngsters will be produced. 


\section{CHAPTER III}

\section{METHODS}

\section{SUBJECTS}

Two subject groups participated in this study. Group I included 10 nonambulatory, speaking children between the ages of 3:0 and 7:0 years. Nonambulatory was operationally defined as a condition where the child is unable to use independent ambulation as the primary mode of mobility. Subject Group II included 10 matched peers who are ambulatory, speaking children, matched for gender and age (within six months) to the subjects in Group I.

Subject criteria for Group I included: (a) mean length of utterance greater than 2.50 calculated from a spontaneous language sample (Miller, 1981); (b) receptive vocabulary within normal limits as measured by the Peabody Picture Vocabulary Test-Revised (Dunn \& Dunn, 1981); and (c) reported vision and hearing within normal limits. Data were collected across North America.

Subject criteria for Group II included: (a) mean length of utterance greater than 2.50 calculated from a spontaneous language sample (Miller, 1981); (2) receptive vocabulary within normal limits as measured by the Peabody Picture Vocabulary Test (Dunn \& Dunn, 1981); 
and (3) reported sensory/motor, vision, and hearing skills within normal limits. All subjects in this group were located in the Portland area.

No criteria for gender, race, or socioeconomic background were set for either group. An informed consent form was approved by the Portland State University Human Subjects Committee.

Table I describes the age, sex, and mean length of utterance (MLU) scores for all subjects.

TABLE I

SUBJECT STATUS

\begin{tabular}{|c|c|c|c|c|c|}
\hline \multicolumn{3}{|c|}{ AMBULATORY } & \multicolumn{3}{|c|}{ NONAMBULATORY } \\
\hline Age & Sex & MLU & Age & Sex & MLU \\
\hline $46 \mathrm{mo}$. & $\mathrm{F}$ & 4.00 & $47 \mathrm{mo}$. & $\mathbf{F}$ & 2.45 \\
\hline $51 \mathrm{mo}$. & $\mathbf{F}$ & 4.60 & $48 \mathrm{mo}$. & $\mathbf{F}$ & 2.69 \\
\hline 53mo. & $\mathbf{F}$ & 4.89 & $48 \mathrm{mo}$. & $\mathbf{F}$ & 4.50 \\
\hline $60 \mathrm{mo}$. & $\mathbf{M}$ & 5.17 & $62 \mathrm{mo}$. & $\mathbf{M}$ & 3.37 \\
\hline $64 \mathrm{mo}$. & $\mathbf{M}$ & 4.23 & $69 \mathrm{mo}$. & $\mathbf{M}$ & 2.03 \\
\hline $65 \mathrm{mo}$. & $\mathbf{M}$ & 5.97 & $65 \mathrm{mo}$. & $\mathbf{M}$ & 4.93 \\
\hline 69mo. & $\mathbf{F}$ & 4.30 & $71 \mathrm{mo}$. & $\mathbf{F}$ & 3.08 \\
\hline $69 \mathrm{mo}$. & $\mathbf{M}$ & 4.66 & $71 \mathrm{mo}$. & $\mathbf{M}$ & 2.90 \\
\hline $71 \mathrm{mo}$. & $\mathbf{M}$ & 3.59 & 70mo. & $\mathbf{M}$ & 4.57 \\
\hline $71 \mathrm{mo}$. & $\mathbf{F}$ & 4.99 & $71 \mathrm{mo}$. & $\mathbf{F}$ & 5.73 \\
\hline
\end{tabular}

PROCEDURE

Data Collection

Nonambulatory, speaking children were recruited throughout 
North America. Information letters explaining the proposed research were sent to private clinicians, speech and hearing clinics and various organizations that serve children with physical disabilities, such as the Pediatric Specialty Group of the American Physical Therapy Association (APTA), members of the International Society for Augmentative and Alternative Communication (ISAAC), and state representatives from the APTA.

Ambulatory, speaking children were recruited from the Portland, Oregon Area. Research assistants collected the data from these subjects by obtaining consent from the families, administering the PPVT, and obtaining a language sample. Families or clinicians interested in participating in the study were sent the following:

1. A cover letter and instructions for parents and clinicians who want to participate in the study (see Appendix A).

2. An informed consent form to be completed by the child's parents (see Appendix B).

3. An audio-cassette tape to be used for recording a language sample.

4. Guidelines for collecting language samples (see Appendix C).

5. Standardized test reporting form and instructions for obtaining expressive and receptive test scores for cooperating clinician (see Appendix D).

6. Self-addressed stamped return envelope.

Parents who agreed to participate completed an Informed Consent Form. A spontaneous language sample was elicited from each subject during a play activity. 


\section{Data Transcription}

The language samples were audio-cassette taped and transcribed according to techniques suggested by Lee (1974), Miller (1981) and BarrieBlackley, Musselwhite, and Rogister (1978). One thousand fifty words were identified for each transcript. The first 50 words were eliminated, resulting in a 1000 word transcript. Confidentiality of the subjects was maintained by assigning each subject a number and entering their respective vocabulary lists into the data base under this number.

\section{Data Entry}

The 1000 words from the language sample were entered into the Advanced Revelations (1990) software, a database, by Cosmos, Inc., on an IBM 386 computer. The following set of rules were used to standardize data entry across subjects:

1. Proper nouns, such as names, are marked with the symbol $\sim$ so they can be identified as unique words. Mom, Dad, Grandma, and Grandpa are not considered proper nouns.

2. Two words that represent a single concept, such as "ice cream, " are hyphenated and entered as one word.

3. Contractions are listed as two separate entries. The rationale is that communication devices do not list both a root word and negation form. A negative marker was used. For example, "can't" became "can" and "n't."

4. Plurals were listed as the singular form. The plural marker "s" was listed as a separate entry. The rational is that communication devices do not list both the root and plural form. A plural marker was used.

5. A word was entered once. 
6. Synonyms and equivalent forms were entered as a standard form. For example, "yeah," "yep," and "uh huh" were entered as "yes."

7. Child forms were entered as is, and identified with the marker *. For example, "owie" became "*owie."

\section{DATA ANALYSIS}

Descriptive and nonparametric statistics were used with these data. A listing of each research question and its corresponding method of analysis follows.

1. Are there differences between the percentages of lexical agreement for ambulatory and nonambulatory matched subject groups when individual language samples are compared to the top $15 \%$ of words in a composite list?

A composite vocabulary list was compiled that consisted of all words from the 20 language samples obtained from children in subject groups I and II. The top $15 \%$ most frequently occurring words in this composite list were extracted. For example, the most frequently occurring word was "I". It occurred 922 times across all 20 subjects. The top $15 \%$ provided the closest cutoff to the top 200 words, making the results easily comparable to another study (Beukelman, Yorkston, Poblete, \& Naranjo, 1984). A percentage of lexical agreement was obtained between each subject's vocabulary list and the top $15 \%$ of the composite list. This is a measurement of the common words in each individual language sample and the entire vocabulary pool (Beukelman, Yorkston, Poblete, \& Naranjo, 1984).

The percent of agreement was calculated by computing the 
proportion of each subject's words that were included in the composite list. The mean, standard deviation, and the range of lexical agreement were calculated for the two groups. A Wilcoxon matched signed rank test (McClave \& Dietrich, 1988) was performed to determine if the two groups have similar probability distributions. It was predicted that the percentages of agreement would be different for the two groups suggesting different pools of vocabulary for the ambulatory and nonambulatory children directly related to their ability to ambulate and interact independently with their environment.

2. Are there differences in the type-token ratios for ambulatory children and nonambulatory children?

Type-token ratios were calculated for each subject by dividing the number of unique words by the total number of words in each language sample. The mean, standard deviation, and range of typetoken ratios were calculated for each subject group and compared. Additionally, a Wilcoxon matched signed rank test (McClave \& Dietrich, 1988) were performed to determine if the two groups had similar probability distributions. This provided an index of lexical diversity within and between the two subject groups. It was expected that the range of type-token ratios for Group I would be lower than Group II due to the greater lexical diversity anticipated from children who are able to ambulate independently and experience their world more. 
3. How many words are used in common to six or more subjects across the two subject groups?

Two consolidated word lists were formed: one for types produced by the nonambulatory speakers; and a second for types produced by their ambulatory speaking peers. For each list, the number of subjects using each type was tabulated. For example, a score of ten indicated that all 10 subjects in one group produced the word, and a score of one indicated that only one subject produced the word. This measure is referred to as a commonality score (Beukelman et al., 1989). Those words that were used by 6 or more subjects were extracted from each of the group lists. The two group lists were compared for exact word matches. For example, the word "be" was used by 10 subjects in the ambulatory group and 8 subjects in the nonambulatory group. The commonality scores for words that appeared on both group lists were compared. The mean and standard deviation of commonality scores for types in each subject group were then calculated to determine the similarity.

4. What words will be present in the lexicon of nonambulatory children and absent in the lexicon of their ambulatory peers?

Words found in the nonambulatory group list were identified. It was predicted that words commonly spoken by nonambulatory children would differ from those words commonly spoken by ambulatory children. These differences would suggest that a fringe vocabulary exists for nonambulatory children that contains words to meet their special needs. These words might need to be highlighted for 
vocabulary consideration when designing expressive communication devices for nonambulatory, nonspeaking children. 


\section{CHAPTER IV}

\section{RESULTS AND DISCUSSION}

This study posed and answered four research questions. They included: 1) Are there differences between the percentages of lexical agreement of ambulatory and nonambulatory matched subject groups when individual language samples are compared to the top $15 \%$ of words in a composite vocabulary list? 2) Are there differences in the type-token ratios for ambulatory children and nonambulatory children? 3) How many words are used in common to six or more subjects in across the two subject groups? and 4) What words will be present in the lexicon of nonambulatory children and absent in the lexicon of their ambulatory peers? In this chapter, the results of each research question will be presented and discussed.

\section{RESULTS}

The first research question investigated whether ambulatory and nonambulatory children produce similar words. This was measured by the percentage of lexical agreement found between each vocabulary list and the top $15 \%$ of words in a composite word list. The composite list consisted of all the different words spoken by all subjects. All twenty language samples, each containing 1000 words, were compiled into a 20,000 word list. The 
unique words (or word types) were identified to create a composite list of vocabulary items. The final composite list contained 1555 types. The top $15 \%$ of that list was extracted and consisted of 219 words. A percentage of lexical agreement was obtained between each subject's 1000-word vocabulary list and the top $15 \%$ of the composite list by computing the proportion of each subject's words that were included in the 219 words. This measure was first discussed by Beukelman et al., (1984) as a reflection of the congruence between word lists. This calculation allows one to study how many words each subject shares in common with the pool of all subjects. Table II presents the data.

\section{TABLE II}

PERCENTAGE OF LEXICAL AGREEMENT BETWEEN AMBULATORY AND NONAMBULATORY SUBJECTS AND A COMPOSITE LIST OF THE 219 MOST FREQUENTLY OCCURRING WORDS

AMBULATORY

PERCENT AGREEMENT

$61 \%$

$58 \%$

$61 \%$

$62 \%$

$56 \%$

$62 \%$

$66 \%$

$63 \%$

$67 \%$

$64 \%$
NONAMBULATORY PERCENT AGREEMENT

53\%

$52 \%$

$58 \%$

$56 \%$

$60 \%$

$53 \%$

$63 \%$

$70 \%$

$53 \%$

55\% 
Table III summarizes these data and presents the mean, standard deviation, and range of lexical agreement percents for the ambulatory and nonambulatory groups.

\section{TABLE III}

SUMMARY OF LEXICAL AGREEMENT PERCENTS FOR THE AMBULATORY AND NONAMBULATORY GROUPS

\section{AMBULATORY NONAMBULATORY}

$\overline{\mathbf{X}}$

SD

RANGE
$62 \%$

.03

$11 \%$
$57 \%$

.06

$18 \%$

Overall, for the ambulatory children, the percentage of lexical agreement ranged from $56 \%$ to $67 \%$ with a mean of $62 \%$ and a standard deviation of .03. This means that an average of 135 out of 219 words appeared in both the child's language sample and the top $15 \%$ of the composite list. For the nonambulatory children, the percentage of lexical agreement ranged from $52 \%$ to $70 \%$ with a mean of $57 \%$ and a standard deviation of .06. This means that an average of 125 words out of 219 words appeared in both the child's language sample and the top $15 \%$ of the composite list.

A Wilcoxon matched signed rank test for differences between related samples was conducted at $\mathrm{p}<.05$ level. There were no significant differences found between the lexical agreement ratios for the two groups of children. 
The second research question posed was: Are there differences in the type-token ratios (TTRs) for ambulatory children and nonambulatory children? Type-token ratios (TTRs) are the ratio of unique words, or types, to all of the words, or tokens, in a given sample. This is a measure often used to describe lexical diversity or the variety of words used by children during a given sample. In order to compare the TTRs for all children, the number of types or unique words spoken were identified in each child's language sample. A type-token ratio was then computed for each sample by dividing the number of types by 1000 tokens.

Table IV (on the next page) presents each subject's TTR. There are two columns. The first column contains the TTRs for each ambulatory child. The second column contains the TTRs for all the nonambulatory children. 
TABLE IV

TYPE-TOKEN RATIOS

AMBULATORY

TTR

.230

.227

.240

.233

.276

.269

.251

.275

.250

.293
NONAMBULATORY

TTR

.220

.229

.264

.317

.220

.205

.264

.273

.232

.271

TTR= Type/Token Ratio

Table V summarizes the data. TTRs for the ambulatory children ranged from .227 to .293 with a mean ratio of .250 and a standard deviation of .023 while the TTRs for the nonambulatory children ranged from .205 to .317 with a mean ratio of .250 and a standard deviation of .032 .

TABLE V

SUMMARY OF TYPE-TOKEN RATIOS

AMBULATORY

$\overline{\mathrm{X}}$

SD

RANGE
.250

.023

.066
NONAMBULATORY

.250

.032 
A Wilcoxon matched signed rank test for differences between related samples was conducted at $p<.05$ level. The two subject groups have similar probability distributions. Therefore, the groups were not significantly different.

The third research question sought to find out how many common words were used by 6 or more subjects in each subject group. Words from each subject group were consolidated to form two composite lists containing 10,000 tokens each. Of the 10,000 tokens collected from the language samples of the ambulatory children, 1003 types were used. Of the 10,000 tokens collected from the language samples of the nonambulatory children, 1078 types were used.

Each group list was analyzed to determine how many subjects used each of the different types. Results are presented in Table VI. The ambulatory group shared 174 words in common to 6 or more subjects; while the nonambulatory group shared 109 words in common to 6 or more subjects. This means that $17 \%$ of the types produced by the ambulatory group and $10 \%$ of the types produced by the nonambulatory group were used by 6 or more subjects.

\section{TABLE VI}

TYPES COMMON TO SIX OR MORE SUBJECTS

$$
\text { Types } \quad \begin{aligned}
& \text { No.words } \\
& \text { common to } 6 \text { or more }
\end{aligned}
$$

$\begin{array}{lll}\text { Ambulatory } & 1003 & 174 \\ \text { Nonambulatory } & 1078 & 109\end{array}$


The data were analyzed to determine the percentage of words in common for both groups at increasing levels of commonality. In other words, what entries were the same in ten out of ten of the lists, in nine of ten lists, eight of ten lists, seven of ten lists and six of ten lists for each subject group? Table VII presents these data. Column 1 lists the level of commonality. Column 2 lists the number of words in common across both groups. Column 3 lists the percentage of words in common for the ambulatory group based on the 1003 types produced. Column 4 lists the percentage of words in common for the nonambulatory group based on the 1078 types produced.

TABLE VII

PERCENTAGE OF WORDS COMMON TO BOTH GROUPS

AMBULATORY NONAMBULATORY

Of 1003 Words. Of 1078 Words.

Commonality No. of Words \% Common to \% Common to

Both Gros. Both Gros.

$\begin{array}{llll}6 & 96 & 10 \% & 9 \% \\ 7 & 79 & 8 \% & 7 \% \\ 8 & 62 & 6 \% & 6 \% \\ 9 & 45 & 5 \% & 4 \% \\ 10 & 32 & 3 \% & 3 \%\end{array}$

As illustrated in Figure 1, the percentage of commonality ranged from $3 \%$ to $10 \%$ for the ambulatory group and $3 \%$ to $9 \%$ for the nonambulatory group. The figure further shows that as the commonality 
across subjects increases, the percentage of words in common to both groups decreases.

$\%$
$C$
$O$
$M$
$M$
$O$
$N$

$T$
$O$

$B$
$O$
$T$
$H$
$G$
$G$
$R$
$P$
$S$
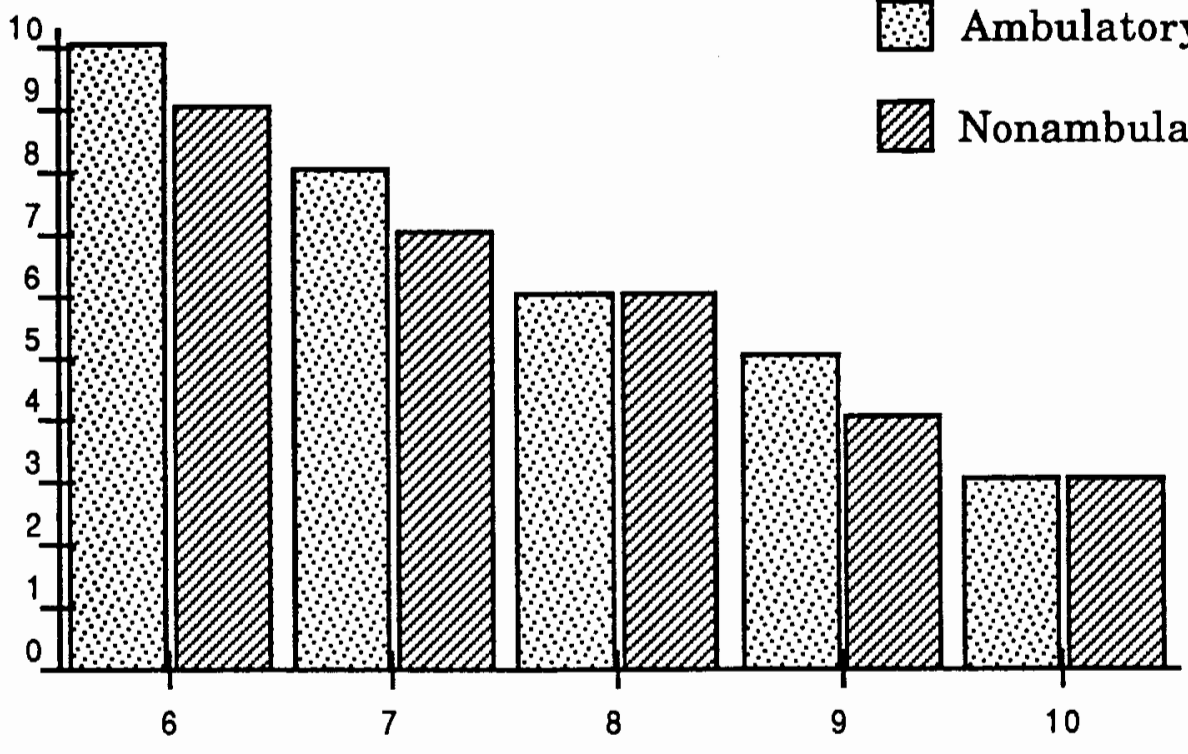

COMMONALTYY

Figure 1. Percentage of commonality for nonambulatory and ambulatory group.

The fourth research question sought to determine what words were present in the lexicon of nonambulatory children and absent in the lexicon of their ambulatory peers. Appendix $\mathrm{E}$ is a listing of 433 words that were used only by nonambulatory children excluding proper names and child forms. This list constitutes $40 \%$ of the total tokens produced by the nonambulatory group and $43 \%$ of all the tokens produced by the ambulatory children. 


\section{DISCUSSION}

This research suggests that regardless of a child's inability to ambulate independently, the words he produces are not significantly different than those of his ambulatory peers and he does not produce a smaller variety of words. Interpretation of the results will be presented in the following pages.

The first research question examined the percentage of lexical agreement of ambulatory and nonambulatory children compared to a composite list of the top $15 \%$ of words spoken by the 20 children. No significant differences were found between the ambulatory and nonambulatory children in the percentage of common words used. If a significant difference had been found, one could argue that the most commonly occurring words come from different vocabulary distributions. Children in the ambulatory group produced an average of $62 \%$ (or 136) words in common with the 219 most frequently occurring words and the nonambulatory group produced an average of $57 \%$ (or 125) words in common. These results are similar to those found by Beukelman, Yorkston, Poblete, \& Naranjo (1984) when they studied the vocabulary of an adult nonspeaking population. They found that with a list of 200 of the most frequently occurring words obtained in their study, an average of $65 \%$ of an individual language sample could be represented. In other words, the percentage of lexical agreement between each vocabulary list and a core list of the 200 most frequently occurring words was $65 \%$. This is similar to the 
averages obtained for both groups of children studied here. Therefore, the distributions for adults and children can be viewed in a similar way. This result lends support to the idea that there is a small core of high frequency words for all children regardless of ambulation that is about the same size as the core lexicon for adults (Beukelman, McGinnis, \& Lowe, 1990).

The second research question examined the differences in type-token ratios for ambulatory and nonambulatory children. The type-token ratios obtained were similar for both groups of children. This suggests that a nonambulatory condition does not predispose language learning in terms of lexical diversity. Children with motor impairments who cannot independently seek many physical cognitive experiences have the same size lexicon as their peers who are able to independently ambulate and experience the world. Motor impairments, per se, do not affect the size of a lexicon.

The type-token ratios obtained in this study were notably low for all children suggesting a need for further examination of the data.

Beukelman et al. (1989) found type-token ratios smaller than those obtained in this study for the same age group. They obtained 3000 tokens and typetoken ratios ranged from .135 to .160 . The present study produced TTRs ranging from .205 to .317 with language sample sizes of 1000 words each. Hess, Haug, and Landry (1989) and others (Andreasen \& Pfohl, 1976; Hess, Sefton, \& Landry, 1986; Richards, 1987) have shown that the basic typetoken ratio decreases significantly as the sample size increases. One can, therefore, conclude that the type-token ratios obtained in the present study 
are congruent with results obtained by Beukelman, Jones, \& Rowan (1989) since their samples contained three times as many tokens as the present study.

The third research question sought to determine how many common words were used by 6 or more subjects in each subject group. No observable differences were obtained between the top words in common for each group. Only $3 \%$ of the types were in common to every child in both groups. As the commonality score decreased, the number of types increased. For example, only 32 words were used by all ten subjects in both groups compared to 96 words common to at least 6 subjects in each group. This means that there are very few words shared by both groups and this finding is repeated throughout the literature. Yorkston et al. (1988) compared a number of standard vocabulary lists to analyze the degree of similarity between them. They found that very few words were contained on all of the lists. Similar to the current findings, they found that as the criteria for appearance on a list was decreased, the number of words increased. They found that only $14 \%$ of the total sample occurred in six or more lists. This study found a comparable percentage of $10 \%$ for the ambulatory and $9 \%$ for the nonambulatory children.

The 96 words in common to six or more children found in this study can suggest a small core vocabulary. Mein \& O'Connor (1960) found a small core when they compared the vocabulary usage of hospitalized, developmentally delayed individuals to nonimpaired individuals.

The final research question resulted in a list of 433 words produced 
only by the nonambulatory children. This relatively small list represents a "fringe" vocabulary for nonambulatory children. These words are completely unique to the nonambulatory group and may be indicative of the perspective of world-experience these nonambulatory preschoolers have. Words such as: HANDICAPPED, REMOTE-CONTROL, STRETCHER, and WHEELCHAIR appeared in the final word list. These may be very important to nonambulatory children but have little use in the vocabulary of their ambulatory peers. This fringe vocabulary should be considered important in the development of AAC system for nonambulatory, nonspeaking children. However, since the previous research questions found that there were no significant differences in lexical diversity or lexical agreement percentages between the two groups, this list should not be held up as a necessary core vocabulary, rather words that should be given consideration when developing an AAC system for a nonambulatory, nonspeaking child. 


\section{CHAPTER V \\ SUMMARY AND IMPLICATIONS}

\section{SUMMARY}

Children with severe physical disabilities often do not have the capabilities for oral communication. Professionals are frequently faced with selecting vocabulary for children who are unable to use vocal output because of severe motor impairments. A child who is nonambulatory may have additional reasons for communicating and sees the world from a different viewpoint than his ambulatory peers. Selecting appropriate words for an initial lexicon that are useful to nonspeaking disabled children that also meet normal language acquisition standards is a concern. This study specifically addresses this concern by looking at the vocabulary differences of ambulatory and nonambulatory preschool children. The purpose of this research project was to compare expressive vocabulary produced by nonambulatory, speaking children with the expressive vocabulary produced by ambulatory, speaking children. It is suggested that the vocabulary of nonambulatory, speaking children might be more appropriate for selecting a lexicon for AAC systems if indeed, they are different from words produced by ambulatory, speaking children.

Ten nonambulatory, speaking children between the ages of 3:0 and 7:0 years and 10 matched peers who were ambulatory served as subjects. 
The ambulatory children were normally developing in respect to receptive and expressive language, vision, and hearing, and sensory/motor skills. The children with mobility restrictions were unable to ambulate independently. A 1000-word language sample of each child was obtained during a play activity. The vocabulary was entered into a computer data base and compared for lexical agreement, lexical diversity, and commonality scores. The vocabulary items obtained were then compared to answer the following questions: 1) Are there differences between the percentages of lexical agreement of ambulatory and nonambulatory matched subject groups when individual language samples are compared to the top $15 \%$ of a composite vocabulary list? 2) Are there differences in the type-token ratios for ambulatory children and nonambulatory children? How many words are used in common to six or more subjects across the two subject groups? and 4) What words will be present in the lexicon of nonambulatory children and absent in the lexicon of their ambulatory peers?

Results indicate that no significant differences exist between ambulatory and nonambulatory children in the percentages of lexical agreement to a composite list of the top $15 \%$ of the most frequently occurring words. This suggests that the commonly occurring words come from the same vocabulary distribution, lending further support to the idea of a high frequency core vocabulary for all children. Low type-token ratios (TTRs) were obtained for all subjects and were not significantly different between the two groups. The TTRs are considered to be similar to those obtained in 
other studies. Ninety-six words were found to be common to six or more subjects in both subject groups and it was found that only 32 words were shared by all subjects. These results are interpreted to mean that nonambulatory children use words that are similar to their ambulatory peers and that the diversity of their vocabulary is not affected by their nonambulatory condition compared to ambulatory children of the same age.

\section{CLINICAL IMPLICATIONS}

This research provides guidelines for professionals who may be in the process of selecting an initial lexicon for nonambulatory, nonspeaking preschoolers. This research project demonstrates that one does not have to teach different vocabulary to children who are not able to ambulate independently. The words produced by both ambulatory and nonambulatory children are similar. Therefore, it can be assumed that the vocabulary use will not differ based on an ambulatory versus nonambulatory condition. The fringe vocabulary list resulting from this study (Appendix E) has clinical value for potential AAC users. Clinicians faced with selecting an initial lexicon for nonambulatory AAC users may use the list of fringe vocabulary as a resource of potentially important words specific to nonambulatory, nonspeaking child.

Furthermore, children who are nonambulatory and exhibit a language disorder could be taught vocabulary parallel to normal language acquisition. The interventions used for ambulatory language disordered 
children should hold true for the nonambulatory language disordered child based on the fact that no significant differences exist in the number of words spoken, types of words used, or similarity of words spoken. However, a fringe vocabulary does need to be considered to meet special motor impairment needs. It is still important to select words based on an environmental inventory, phonological sequence, and the content, form, and use of the vocabulary (Holland, 1979; Lahey \& Bloom, 1978).

A closer look at the MLU scores obtained for the nonambulatory subjects versus the ambulatory subjects shows that the nonambulatory children used shorter utterances than their ambulatory peers. Although the overall number of words produced by the nonambulatory group do not differ from their ambulatory peers (1000 words) and the diversity of their vocabulary is similar, the length of their utterances are shorter. When a clinician is selecting an initial lexicon for nonambulatory AAC users, the length of utterances available should be taken into consideration.

Children who do not ambulate independently are likely to have different reasons for communicating. This group uses similar words as children who do ambulate independently, yet, one must consider the pragmatic function of the words spoken. It is possible that the nonambulatory children use their words for functions such as requesting and labeling versus the more advanced functions such as commenting and conversational turn-taking. When establishing an initial lexicon for nonambulatory AAC users, consideration must be given to the potential functions of the words chosen and teaching various functions may be 
necessary.

\section{RESEARCH IMPLICATIONS}

Although the lexical diversity of nonambulatory children is equal to that of ambulatory children, the exact types of words used by each group may be different. Comparing the semantic classes present in the expressive vocabulary of the ambulatory and nonambulatory preschool populations is an important research consideration. Analysis by semantic categorization is the next logical step. It may be found, for example, that the nonambulatory children produce a greater number of words that represent medical needs, toileting, or limited physical activities. On the other hand, the words spoken by the ambulatory children may represent play and physical activities. Information such as this would lend further insight into the distinctive lexical items needed for nonambulatory, nonspeaking children.

Nonambulatory and ambulatory children may have distinctive high frequency core vocabularies of relatively small size, then share a core vocabulary of moderate size, and finally, a fringe vocabulary which must be chosen for each individual child based on the factors presented by Lahey and Bloom (1978) and Holland (1979). This could be studied by comparing the percentage of lexical agreement to various levels of frequency of occurrence (i.e. top $5 \%, 10 \%, 15 \%, 20 \%, 25 \%$, etc.).

Words that are common to many subjects in one group yet not very 
common to subjects in the other group may also provide useful information. In this study, only words that were used by six or more subjects in each subject group that were exactly the same were analyzed. Examination of words that are used by many subjects in the nonambulatory group could be conducted by comparing the frequency of usage for words used by six or more subjects in that group to the ambulatory group. These words may be suggestive of specific words to be included in a high frequency core vocabulary database. A further comparison of these words to the percentage of lexical agreement to the top $5 \%$ or $10 \%$ of a composite list as suggested above, may show a positive correlation and further the stability of a high frequency core vocabulary for nonambualtory children.

A further consideration may be to obtain type-token ratios in a different manner than obtained in the present study. A play situation was used to elicit the language samples. Although these play situations were intended to represent rituals encountered in a typical day, certain play activities may have skewed the actual production potential of many children. Hess, Haug, \& Landry (1989) showed that more reliable typetoken ratios can be obtained by changing the topic more frequently at regular intervals. Beukelman, McGinnis, Lowe (1989) stress the need to have vocabularies for different situations. A school lexicon is different than a family dinner lexicon. This study only sampled one situation.

A final area for consideration in research is determining whether the core words shared by subjects in both groups are truly important for nonambulatory, nonspeaking children. This can only be determined by a 
process of social validation. Social validation can be performed by recording the frequency and commonality of use of different words on the core vocabulary. The adults, or in some cases an electronic data collector in a communication device, would be required to record the words actually used by a number of nonambulatory, nonspeaking children for an extended period of time and over a variety of situations. Obviously, this will be a difficult process but one that is necessary to determine which words allow and encourage communication and therefore truly belong on a core vocabulary.

In conclusion, the research questions presented and answered in this research project are interpreted to mean that nonambulatory children use words that are similar to their ambulatory peers and that the diveristy of their vocabulary is not affected by their nonambulatory condition compared to ambulatory children of the same age. Further research is necessary to determine if differences exist in the pragmatic functions and semantic categorization of the words produced by nonambulatory, speaking children and their ambulatory peers. Clinically, the fringe voabulary list resulting from this study has value for selecting lexicon items for nonambulatory AAC users. 


\section{REFERENCES}

Advanced Revelation [Computer program] (1990). USA: Revelation Technologies, Incorporated.

Andreasen, N.J., \& Pfohl, B. (1976). Linguistic analysis of speech in affective disorders. Archives of General Psychiatry, 33, 1361-1367.

Barrie-Blackley, S., Musselwhite, C.R., \& Rogister, S.H. (1978). Clinical Language Sampling: A Handbook for Students and Clinicians. Danville, IL: The Interstate Printers and Publishers, Inc.

Bates, E., Bretherton, I., \& Snyder, L. (1988). From first words to grammar: Individual differences and dissociable mechanisms. New York: Cambridge University Press.

Baumgart, D., Johnson, J., \& Helmstetter, E. (1990). Augmentative and Alternative Communication Systems for Persons with Moderate and Severe Disabilities. Baltimore, Maryland: Paul H. Brookes Publishing Co., Inc.

Benedict, H. (1977). Early lexical development: comprehension and production. Journal of Child Language, $6,183-200$.

Beukelman, D.R., Yorkston, K. M., Poblete, M., \& Naranjo, C. (1984). Frequency of word occurrence in communication samples produced by adult communication aid users. Journal of Speech and Hearing Disorders, $\underline{49}, 360-367$.

Beukelman, D.R., Jones, R.S., \& Rowan, M. (1989). Frequency of word usage by nondisabled peers in integrated preschool classrooms. Augmentative and Alternative Communication, 5, 243-248.

Beukelman, D.R., McGinnis, J., \& Morrow, D. (1991). Vocabulary Selection in Augmentative and alternative Communication. Augmentative and Alternative Communication, 7, 171-185.

Blau, A. (1983). Vocabulary selection in augmentative communication, where do we begin? In $\mathrm{H}$ Winitz (ed.), Treating Language Disorders: For Clinicians by Clinicicans. Baltimore: University Park Press, 205234.

Carlson, F. (1981). A format for selecting vocabulary for the nonspeaking child. Language. Speech, and Hearing Services in Schools, 12, 140-145. 
Clark, E. (1973). What's in a word? On the child's acquisition of semantics in his first language. In T. Moore (Ed.), Cognitive Development and the Acquisition of Language. New York: Academic Press.

Dahl (1965). Vineland Adaptive Behavior Scales. circle Pines, MN: American Guidance Service.

Dale, P., Bates, E., Reznick, S., \& Morisset, C. (1989). The validity of a parent report instrument of child language at 20 months. Journal of Child Language, 16, 239-250.

Dunn, L. (1981). Peabody Picture Vocabulary Test-Revised. Circle Pines, MN: American Guidance Services.

Fleming, C. P. (1968). The verbal behaviour of hydrocephalic children. Developmental Medicine and Child Neurology, 15, 74.

Fristoe, M., \& Lloyd, L. (1980). Planning an initial expressive sign lexicon for persons with severe communication impairment. Journal of Speech and Hearing Disorders, 45, 170-180.

Goldin-Meadow, S., Seligman, M. \& Gelman, R. (1976). Language in the two-year old. Cognition, 4, 189-202.

Harris, D. \& Vanderheiden, G. (1980). Enhancing the development of communicative interaction. In R. Schiefelbusch (Ed.); Nonspeech Language and Communication. Baltimore: University Park Press.

Hess, C. W., Haug, H. T., \& Landry, R. G. (1989). The reliability of typetoken ratios for the oral language of school age children. Journal of Speech and Hearing Research, 32, 536-540.

Hess, C. W., Sefton, K. M., Landry, R. G. (1986). Sample size and typetoken ratios for oral language of preschool children. Journal of Speech and Hearing Research, 29, 129-134.

Holland, A. (1975). Language therapy for children: Some thoughts on context and content. Journal of Speech and Hearing Disorders, 40, 514523.

Horn, D., Lorch, E., Lorch, R., and Culatta, B. (1985). Distractibility and vocabulary deficits in children with spina bifida and hydrocephalus. Developmental Medicine and Child Neurology, 27, 713-720.

Karlan, G. R., \& Lloyd, L. L. (1983). Considerations in the planning of intervention: Selecting a lexicon. The Association of the Severely Handicapped Journal, 8, 13-25. 
Lahey, M. \& Bloom, L. (1977). Planning a first lexicon: Which words to teach first. Journal of Speech and Hearing Disorders, 42, 30-349.

Lee, L. (1974). Developmental Language Analysis. Evanston, IL: Northwestern University Press.

Love, R. \& Webb, W. (1986). Neurology for the Speech-Language Pathologist. Stoneham, MA: Butterworth Publishers.

Lowe, D. (1988). Vocabulary Selection for Augmentative Communication: A comparison of three techniques. Augmentative and Alternative Communication,

McCarthy, J. J. \& Kirk, S. A. (1961). Ilinois Test of Psycholinguistic Abilities, Experimental Edition. Urbana, nlinois: Institute for Research on Exceptional Children.

McClave, J. T. \& Dietrich, F. H. (1988). Statistics. San Francisco, CA: Dellen Publishing Company.

Mein, R. \& O'Connor, N. (1960). A study of the oral vocabularies of severely subnormal patients. Journal of Mental Deficiency Research, 4, 130-143.

Meyers, L., Andersen, C., and Liddicoat, C. (1984). Perceived communication needs of developmentally delayed nonspeaking children. The Psychological Record, 34, 55-68.

Miller, J. (1981). Assessing Language Production in Children. Austin, TX: Pro-Ed.

More, L. (1990). The Creation of a Core Vocabulary for Initial Lexicon Selection for Nonspeaking Preschool Children. Unpublished master's thesis, Portland State University, Portland, OR.

Morrow, D. R., Beukelman, D. R., \& Mirenda, P. (1989). Vocabulary selection for augmentative communication systems: A comparison of three techniques. Unpublished Master's thesis, University of Nebraska, Lincoln.

Nelson, K. (1973) Structure and strategy in learning to talk. Monographs of the Society for Research in Child Development, 38.

Owens, R. E. (1988). Language Development. Columbus, OH: Merrill Publishing Co.

Porter, P. (1987). Augmentative communication: Selection of an initial vocabulary. Physical and Occupational Therapy in Pediatrics, 7, 79-90. 
Reichle, J., Williams, W., and Ryan, S. (181). Selecting signs for the formulation of an augmentative communicative modality. The Journal of the Association of the Severely Handicapped, 6, 48-56.

Rescorla, L. (1989). The language development survey: a screening tool for delayed language in toddlers. Journal of Speech and Hearing Disorders, 54, 587-599.

Reynell, J. (1984). Developmental Language Scale. London: NFER Nelson.

Reznick, J. \& Goldsmith, L. (1989). A multiple form word production checklist for assessing early language. Journal of Child Language, 16, 91-100.

Richards, B. (1987). Type/token ratios: What do they really tell us? Journal of Child Language, 14, 201-209.

Schwartz, E. (1974). Characteristics of speech and language development in the child with myelomeningocele ad hydrocephalus. Journal of Speech and Hearing Disorders, $39,465-468$.

Swisher, L. \& Pinsker, E. (1971). The language characteristics of hyperverbal, hydrocephalic children. Developmental Medicine and Child Neurology, 13, 746-755.

Tew, B. (1979). The "cocktail party syndrome" in children with hydrocephalus and spina bifida. British Journal of Disorders of Communication, 14, 89-101.

Williamson, G. (1987). Children With Spina Bifida. Baltimore, Maryland: Paul H. Brookes Publishing Co., Inc.

Wilson, K. (1980). Selection of a core lexicon for use with graphic communicative systems. Journal of Child Communication Disorders, $\underline{4}$, 111-123.

Yorkston, K., Dowden, P., Honsinger, M., Marriner, N., and Smith, L. (1988). A comparison of standard and user vocabulary lists. Augmentative and Alternative Communication, 4, 189-203.

Yorkston, K., Smith, K., And Beukelman, D. (1990). Extended communication samples of augmented communicators: A comparison of individualized versus standard single-word vocabularies. Journal of Speech and Hearing Disorders, 55, 217-224. 


\section{APPENDIX A}

COVER LETTER AND INSTRUCTIONS TO PARENTS AND CLINICLANS 
Dear Parents:

I am a researcher and a speech-language pathologist at Good Samaritan Hospital in Portland, Oregon where I help children who are not able to talk due to physical disabilities. specifically. I make communication boards for children with cerebral palsy who cannot speak. The parents, teachers, and I choose words and pictures that go on the boards, and then teach the children to point to the items they want to say.

I am looking for children between the ages of 3 and 6 years old who are nonambulatory and can talk to participate in a simple research project. The project will improve the ways that we choose the vocabulary for the communication boards. I invite you and your child to be part of our project. You can help parents communicate with nonspeaking children, and improve education and language learning of children with severe physical disabilities.

Your participation in the study takes only one hour at home. We simply ask you to make a list of the 110 most important words that your child would need if he/she could not speak and was using a communication board. All you need to do is listen to the words that your child uses for a day or so, and then make a list of the 110 most frequently used words.

We also ask your permission to have your children participate in this study. Your speech-language pathologist will take the children out of the classroom for 2 sessions, about 45 minutes each, to tape record their speech while they are playing. We will also measure the children's vocabularies by having them point to pictures in two language tests. The results of the language testing and the audio-tape will be sent to me in portland so that I can see what common words are used by nonambulatory, speaking children. The names of the children will be withleld and your speech pathologist will only include their initials when the information is sent to Portland.

The attached Informed consent Form includes a more detailed description of the study. If you are interested, please read and sign the Informed Consent Form, and fill out the vocabulary list with words you would choose for your child. please return both forms in the enclosed. stamped envelope. We will receive the audio-tape in the mail separately from school.

Thank you for participating! If you have any questions, please call me collect at (503) 229-7266. I look forward to assisting nonspeaking children with cerebral palsy and their families communication better through your help. 


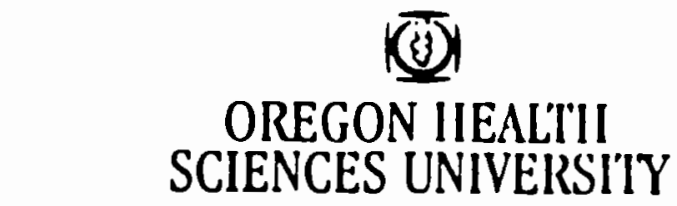

3181 S.W. Sain Jack.son Park Hosacl, 1.226

Pordand, Oregon 97201.3098 (SU3) 491.7772 liax (5U3) 114.7212

scbool of Medlatme, Department of Neurmingy

Dear Cooperating Clinician:

We certainly appreciate your willingness to participate in our research endeavorg on vocabulary selection for augmentative communication. Below we have listed the tasks that need to be completed for each subject.

1. Identify a child who fits our subject criteria. The subject criteria are: - between the ages of 3 years; 0 months and 6 years: 4 months

- nonambulatory condition. where the child cannot use ambulation as the primary mode of mobility

- adequate oral motor skills to rely on speech as the primary mode of communication

- within normal receptive and expressive language skills as measured by formal tests

2. Contact the child's parents and ask if they are willing to participate in this study. If they agree, then the parents' package should be sent home with the child.

Please instruct the parents to:

a) Read and sign the Informed Consent form.

b) Complete the vocabulary list by writing down the 110 words that their child would need if he/she could not talk.

c) Send the Informed Consent form and the vocabulary list to Dr. Melanie Fried-oken in the enclosed envelope.

3. Elicit a language sample from the child. We will enter 1000 words produced by the child into our data base. From our recent experience of transcribing 30 children between the ages of 3 to 6 years. We have found that 60 to 90 minutes of spontaneous speech produces a language corpus that contains at least 1000 intelligible, transcribe-able words. Since this is a rather lengthy process we often elicited language in two sessions with the younger children. 
We have included language sampling suggestions for you in this mailing. We ask you to use your professional judgement and language sampling experience to help us with data collection. It is difficult to ask cooperating clinicians to collect language samples for us since there will be non-standard elicitation styles used. Given our limited subject pool in the Portland area, however, your language sample is the best way to collect data.

4. Administer the Peabody Picture Vocabulary Test-Revised, either test $L$ or $M$, and record the raw score on the enclosed data collection form.

5. Administer the expressive portion of the Northwestern Syntax screening Test and report the score on the enclosed data collection form.

Mail the audio-cassette and data collection form to Dr. Melanie Fried-oken in the enclosed cassette mailer.

If you have any questions at all, please call Dr. Fried-oken at 503-229-7266. Thank you again for your time, cooperation, energy and concern. We will be happy to share our results with you as soon as all the data are collected and analyzed.

Sincerely.-

Muiaci Fuedoken

Melanie Fried-oken, Ph. D.

Clinical Researcher/ Coordinator

Augmentative Communication Service 
APPENDIX B

INFORMED CONSENT FORM 


\author{
(3) \\ OREGON HEALTH \\ SCIENCES UNIVERSITY \\ 3181 S. W. S2m jackson Park Road, L226 \\ Pordind, Oregon 97201.3098 (503) 494-T772 F2x (503) 494-7242 \\ Scbool of Medicime, Department of Neurology
}

OREGON HEALTH SCIENCES UNIVERSITY

Consent Form

\begin{abstract}
A. TITLE: VOCABULARY NEEDS OF THE NONSPEAKING CHILDREN AS DETERMINED BY CAREGIVERS
\end{abstract}

PRINCIPAL INVESTIGATOR: MELANIE FRIED-OKEN, PhD

B. PURPOSE AND DESCRIPTION OF STUDY: Some children who have cerebral palsy cannot control their oral muscles to speak effectively. They must use communication aids to express their thoughts and needs. Many children point to pictures on communication boards and books. Others use electronic devices, such as Speak $n$ Spell or Apple computers, that speak for a person. These aids are referred to as augmentative communication systems.

Every augmentative communication system must present words or pictures to children so that they can choose what they want to say. For example, a child must be able to point to printed words or a picture of ice cream when asked, "What do you want for dessert?"

The task of selecting the words to put on a communication board for a nonspeaking child is a very difficult one. Parents, family members, teachers and therapists must decide what words and sentences the nonspeaking child might want (or need) to say. The vocabulary must give the child as much communication freedom as possible.

Unfortunately, most comrunication boards only contain between 4 and 400 words. Since you can't put every word in a language on a communication aid, most vocabulary lists are restrictive. A nonspeaking child cannot say everything he wants to. The problem facing adults who make communication aids for nonspeaking children is: "What words should I choose?"

The purpose of this research study is to compare vocabulary lists that are chosen for speaking and nonspeaking children, with and without mobility problems, between the ages of 3 to 6 years old. The words that are commonly selected for all children will be shared with adults who make communication aids. 
C. PROCEDURES: Participation in this study will involve about one hour of my time which can be in my chosen location. I will simply be asked to make a list of 110 words that my child would use to communicate if he/she could not speak. The children will participate in the study also. They will be audio-tape recorded for about one hour while they are playing with toys and talking. The audiotapes will be transcribed so that the investigator can see what words the children chose to speak. The tapes will be destroyed after the research project is finished. The children will also take a language test to judge that they understand language within normal limits. The language test will take about 20 minutes and involve my child pointing to pictures when their names are given. My child will take the test during the play activity session, in my location of choice.

D. RISKS AND DISCOMFORTS: There are no significant risks associated with this study. My child and I can stop anytime we feel uncomfortable during the task.

E. BENEFITS: No specific benefits will be derived by participants in this study other than supplying common word lists to nonspeaking children. The results for medical science will help speech-language pathologists and health professionals who make communication aids select. the least restrictive and most useful vocabulary for augmentative communication.

F. CONFIDENTIALITY: To ensure confidentiality, our names will not be used in this study. Initials and numbers will replace our names so our identities remain private. Neither me or my child's name nor identify will be used for publication or publicity purposes.

G. COSTS: No costs will be applied whatsoever. All required materials will be sent to me. Upon completion of our participation, we will send the materials back to you in pre-stamped, selfaddressed envelopes.

H. LIABILITY: The oregon Health Sciences University, as an agency of the State, is covered by the State Liability Fund. If we suffer any injury from the research project, compensation would be available to use only if we establish that the injury occurred through the fault of the University, its officers, or employees. If we have further questions, we will can Dr. Michael Baird at (503) 494-8014. 
I. CONSENT: I have read this consent form and have discussed with Dr. Fried-oken or her representative the procedures described above. I have been given the opportunity to ask questions, which have been answered to my satisfaction. I understand that I can

telephone Dr. Fried-oken, collect, at (503) 494-7772 to answer any questions I still might have.

I understand that as a participant in this study my identity and my child's identity, records and data relating to this research study will be kept confidential.

I understand that I am free to refuse to participate or to withdraw from participation in this study at any time and it will in no way affect my relationship with, or treatment at the oregon Health Sciences University.

I will receive a copy of this consent form.

My signature below indicates that I have read the foregoing and agree, for my child and me, to participate in this study:

DATE

PARENT

DATE

WITNESS

Please print child's name:

Child's date of birth:

Child's address: 


\section{APPENDIX C}

GUIDELINES FOR COLLECTING LANGUAGE SAMPLES 


\section{Guidelines for Collecting Language Samples}

We ask you to elicit a language sample that contains at least 1000 intelligible, transcribe-able whole words. We suadest that you tape about 60 to 90 minutes of spontaneous speech. This could be done in two or three sessions. Indicate the child's initials and the dates of the recordings on the cassette.

We are trying to elicit common words that are used in a child's daily environment. We have found that a doll house and dolls create a familiar family setting for frequent vocabulary. A Fisher-Price "Little People's" doll house with dolls, cars and furniture were the stimulus materials used with the speaking, ambulatory control subjects.

Introduce a number of routines that are included in a child's daily life. These could include:

- waking up and getting dressed

- making or eating breakfast/lunch/supper

- going to school or day care

- going to the store

- family outings

- watching TV

- playing - toys and games

- snacks

- nap time

- bedtime - baths, bedtime story etc.

Some children are responsive to these suggestions and will

talk about them. others will not be directed by an adult and will introduce the routines that they want to talk about. Don't be too concerned if the child refuses to talk about these routines!

Please repeat those utterances which you feel might be unintelligible to the transcriber. It is better to repeat too much than not repeat at all!

Please note the location and dates of the samples and any comments on the data collection form.

If you have any questions or concerns about the guidelines, feel free to call Dr. Melanie Fried-Oken or Lillian More, collect, at (503) 229-7266. We thank you for your help. 


\section{APPENDIX D}

STANDARDIZED TEST REPORTING FORM AND INSTRUCTIONS 
DATA COLLECTION FORM

Please complete this form and return it with the cassette of the language samples.

Clinician's Name:

Business Address:

Phone Number:

Child's Initials:

Birthdate:

Sex:

School:

Date(s) Language Sample(s) Recorded:

Situation:

Peabody Picture Vocabulary Test-Revised Raw Score:

Northwestern Syntax Screening Test (Expressive Portion)

Raw Score:

Comments :

Thank you for your help! Please indicate below if you are interested in receiving a copy of the transcribed language sample or a list of the child's 100 most commonly used words. 


\section{APPENDIX E}

LIST OF WORDS UNIQUE TO NONAMBULATORY GROUP 
LIST OF WORDS UNIQUE TO NONAMBULATORY GROUP

\begin{tabular}{|c|c|c|}
\hline T & ACCIDENT & AGE \\
\hline $\mathrm{AHHH}$ & AIRPLANE & ALARM \\
\hline ALIGNED & ALL-DONE & ANGEL \\
\hline ANIMAL & APPLE & AS \\
\hline AWFUL & AWHILE & B \\
\hline BABY-SITTER & BABYSITS & BACKPACK \\
\hline BAKE & BALLOON & BANANA \\
\hline BAR & BARKING & BASEBALL \\
\hline BATH & BEAN & BEANBAG \\
\hline BERRY & BESDE & BEST \\
\hline BILL & BLANKET & BLEW \\
\hline BLOW & BLUE & BOOM \\
\hline BORROW & BOTHER & BOTTLE \\
\hline BOUGHT & BOUNCED & BOW \\
\hline BOWL & BRACE & BREAD \\
\hline BREAK & BRICK & BRINGS \\
\hline BROCCOLI & BROUGHT & BROWN \\
\hline BUILT & BUMPING & BUNNY \\
\hline BURP & BURRITO & BUS \\
\hline BUSH & BUTTON & BYE \\
\hline CALORIE & CANDLE & CANNON \\
\hline CANTELOUPE & CARROT & CASH-REGISTER \\
\hline CAUGHT & CAUSE & CHECK-OUT \\
\hline CHEESE & CHIN & CHURCH \\
\hline CINNAMON & CLEAN & CLEAR \\
\hline CLICK & CLOCK & COOPERATE \\
\hline CORN & COUNT & COVER \\
\hline COW & CRACKER & CRAWLED \\
\hline CREAM-OF-WHEAT & CRUNCHY & CUCKOO-CLOCK \\
\hline CUP & DANCING & DAUGHTER \\
\hline DESK & DIAPER & DIDN'T \\
\hline DINING-ROOM & DINING-TABLE & DINOSAUR \\
\hline DOCTOR & DRANK & DRIVER \\
\hline DUCK-DUCK-GOOSE & DUMB & DUMP \\
\hline $\mathrm{EACH}$ & EASTER & EIGHT-OCLOCK \\
\hline EIGHT-THIRTY & EIGHTEEN & ELELPHANT \\
\hline ELEVATOR & ELF & EMPTY \\
\hline EVER & FALLING & FEATHER \\
\hline FEED & FEEDING & FEEDS \\
\hline FEVER & FIRE-TRUCK & FIREMAN \\
\hline FLASHLIGHT & FLOCKING & FOOT \\
\hline FORK & FOURTEEN & FRENCH-FRY \\
\hline FRIDAY & FROG & FRUIT \\
\hline FRUIT-ROLL-UP & GARBAGE & GATE \\
\hline
\end{tabular}


GIVING

GOOEY

GRAHAM

GROUND

HAIRBRUSH

HAT

HAULS

HEAVEN

HID

HOCKEY

HOT-DOG

HURRY

JAM

KEY

KNIFE

KNOWS

LADDER

LANDED

LIBRARY

LIVED

LOSE

MADE

MAILBOX

MEANS

MESS

MIRROR

MOON

MRS

NAIL

NECKLACE

NINE

NOODLE

NUMBER

OCLOCK

OPERATED

ORNAMENT

PAINT

PARADE

PAY

PEACH

PEW

PIG

POLE

PRESENT

PUCK

PUPPY

QUIET
GLOVE

GOSH

GRANDPA

GROUNDED

HANDICAPPED

HAUL

HAY

HELICOPTER

HIMSELF

HOMEWORK

HOUND

ICE-CEREAL

JELLY-BEAN

KULED

KNOCKED

KONK

LADY

LASAGNA

LIGHT-SWITCH

LIVING-ROOM

LOTION

MAGIC

MAILING

MEETING

MICROWAVE

MISTAKE

MOUNTAIN

MUSH

NAPKIN

NEITHER

NO-WAY

NOWHERE

ORANGE

OF-COURSE

ORDER

OUTTA

PAJAMAS

PASS

PAYING

PEAR

PICKS

PILGRIM

POPPED

PRESIDENT

PUFF

PUSHING

QUIETLY
GOOD-MORNING

GOTCHA

GRAY

GROWGROWL,

HANG

HAULER

HEADACHE

HERS

HIPPOPTUMUS

HORSE

HUFF

INDIAN

KEPT

KITTEN

KNOT

KONKED

LAMP

LAY

LION

LOOSE

LOVE

MAID

MARKER

MERRY-CHRISTMAS

MIDDLE

MONEY

MOVED

MYSELF

NAUGHTY

NIGHT-NIGHT

NOISY

NUGGET

OAT-BRAN

OLIVE

ORDINARY

OVEN

PAPER

PASTE

PEA

PET

PICTURE

PLANE

PRAYER

PRIZE

PUMPKIN

PUTS

RABBIT 
RADIO

RAINING

READER

RESTED

RIPPED

ROCKS

SAUSAGE

SAYING

SCAREY

SCRUB

SEMI

SEVEN-THIRTY

SHAVE

SHIRT

SHOWER

SING

SIX-THIRTY

SKUNK

SMASHED

SOMETIME

SORE

SPEAKER

SPOON

STANDING

STEAMY

STINKY

STRAW

STUPID

SUPER

TAPE

THANK

TIGHT

TOOTH

TRAIN

TRIED

TUCK

TURNED

TWINKLER

UNTIED

USED

WASH

WEEKEND

WHIP

WHOLE

WINNER

WORKS

YESTERDAY
RAG

RAISIN

RECESS

REWIND

ROCK

ROLL

SAVED

SCARED

SCARING

SECOND

SEND

SEW

SHAVED

SHOPPER

SHUT

SINK

SIXTEEN

SLAMMING

SNOWMAN

SON

SORRY

SPEND

SPRAYED

START

STICKER

STOCKING

STRETCHER

SUN

SURPRISE

TEAM

THIRTY

TOAST

TOUCH

TREE

TROUBLE

TUCKED

TWELVE

TWO-OCLOCK

UPSIDE-DOWN

USETA

WEAR

WHEELCHAIR

WHIPPED

WIND

WOODS

WORRIED

YUCK
RAINBOW

RAT

REMOTE-CONTROL

RICE

ROCKING-CHAIR

ROSE

SAW

SCARES

SCREAMED

SELF

SERGEANT

SHARE

SHAVING

SHOT

SIGN

SIX-OCLOCK

SIZE

SMARTY

SOLID

SOON

SPAGHETTI

SPILLED

STACK

STAYED

STICKY

STOVE

STUCK

SUNBURNED

TALL

TEN-THIRTY

THROAT

TOMATOE

TOWER

TRICKY

TRUNK

TURKEY

TWIN

TYPE

USE

VIDEO

WEARS

WHILE

WHITE-HOUSE

WING

WORD

YAHO

YUCKY 